\title{
MANAGEMENT OF EFFICIENCY OF THE ENERGY AND RESOURCE SAVING INNOVATIVE PROJECTS AT THE PROCESSING ENTERPRISES
}

\author{
Mykola Zos-Kior' ${ }^{1}$, Iryna Hnatenko² ${ }^{2}$ Oksana Isai ${ }^{3}$, Iryna Shtuler ${ }^{4}$, \\ Oleksandr Samborskyi ${ }^{5}$, Viktoriia Rubezhanska ${ }^{6}$ \\ ${ }^{1}$ Prof. Dr Sc. (Econ), Poltava State Agrarian Academy. Skovoroda str. 1/3. 36003. Poltava. Ukraine. \\ Phone Number+380501325043,E-mail address zoskior@gmail.com \\ ${ }^{2}$ Assoc. Prof. PhD, Kyiv National University of Technologies and Design. Nemyrovycha-Danchenka str. 2. \\ 01011. Kyiv. Ukraine.Phone Number+380661076939,E-mail addressq17208@ukr.net \\ ${ }^{3}$ Assoc. Prof. PhD, Kyiv National Economic University named after Vadym Hetman. Peremohy Ave 54/1. 03057. \\ Kyiv. Ukraine. Phone Number +38(067)5042990, E-mail address isay.oksana@ gmail.com \\ ${ }^{4}$ Prof. Dr Sc. (Econ). National Academy of Management. Ushynskogo str. 15. 03151. Kyiv. Ukraine. \\ Phone Number+380507633413.E-mail address shkirka2002@ukr.net \\ ${ }_{5}^{5}$ Assoc. Prof. PhD, Kyiv National Economic University named after Vadym Hetman. Peremohy Ave 54/1. 03057. \\ Kyiv. Ukraine. Phone Number +380667047361, E-mail address iaccaunting@ gmail.com \\ ${ }^{6}$ PhD of Econ. Luhansk Taras Shevchenko National University. Gogol str. 1. 92700. Starobilsk. Ukraine. \\ Phone Number+380953081789. E-mail address rubezhiik@gmail.com
}

Received 2910 2020; Accepted 14122020

\begin{abstract}
Introduction and optimization of the use of the energy and resource saving innovations in the production process of enterprises is one of the main conditions ensuring stable development of the economy of any country. Due to the high level of consumption of fuel, energy raw and auxiliary materials, the introduction of these innovations is relevant for processing plants. At the same time, management of the energy and resource saving innovations at these enterprises is complicated by the lack of investment in the processing industry as a whole, low efficiency of use of the enterprise own financial resources and high level of the credit risk inherent in the innovation projects. In this regard, the aim of the article is to develop a methodology for evaluating the economic efficiency of innovative energy and resource saving projects. To achieve this goal, the following research methods were used: system analysis, economic and mathematical modeling, abstract and logical method. The proposed as a result of the study method of assessing economic efficiency of innovative projects on the energy and resource saving can be used in the process of integrated management of the energy and resource saving innovations at the processing plants by implementing basic standards of resource management taking into account possible risks.
\end{abstract} methodology.

Keywords: processing enterprise, management, resources, energy, innovative project, investment,

JEL Codes: D24, O32.

\section{Introduction}

Given the strengthening of the national economies integration into the world economy, one of the main conditions ensuring stable economic development of any country is the introduction and optimization of energy and resource saving innovations in the production activities of enterprises. At the same time, the use of these innovations is relevant for processing enterprises due to the high level of consumption of fuel, energy, raw and auxiliary materials (Hnatenko, Kuksa, Naumenko, Baldyk, Rubezhanska, 2020; Kuksa, Hnatenko, Orlova-Kurilova, Moisieieva, Rubezhanska, 2019).

Copyright (C) 2020. Published by Vytautas Magnus University. This is an open access article distributed under the terms of the Creative Commons Attribution Non-Commercial 4.0 (CC BY-NC 4.0) license, which permits unrestricted use, distribution, and reproduction in any medium provided the original author and source are credited. The material cannot be used for commercial purposes. 
However, management of the energy and resource saving innovations at these enterprises is complicated by the lack of investment in the processing industry as a whole, low efficiency of use of the enterprise own financial resources, and high level of credit risk inherent in innovation projects (Bilan, Zos-Kior, Nitsenko, Sinelnikau, Ilin, 2017; Kuksa, Shtuler, Orlova-Kurilova, Hnatenko, Rubezhanska, 2019; Gryshko, Zos-Kior, Zerniuk, 2018). In this regard, the priority in the development of the processing industry is the constant modernization of production technologies, optimization of the interaction of financial and credit institutions with processing enterprises, development and implementation of the economic management mechanisms that will ensure the most efficient use of the resources available for the enterprises.

The scientific works of many scientists are devoted to the study of innovations in the field of energy and resource saving and the organization of their implementation in the production activities of enterprises in various sectors of the economy (McAdam, Dunn, McCall, 2014; Stroud, Evans, Weinel, 2020). Thus, Xu, Wang, Chiu, Ren (2020) using the financial and economic indicators of 23 heat and power companies in China conducted an empirical study of the impact of innovative technologies on the energy and resource saving efficiency at these enterprises. Zhang, Li, Han, Geng, Chu (2020) proposed the AP-MNR method for energy saving and optimization of resources for real production processes at the processing plants. Zhang, Huang, Yang (2020) and Cunha et al. (2020) conducted a study of the impact of energy saving measures on the financial indicators of the enterprises in China and Portugal. Li, Zeng, Xiao, Cao, Yang, Zhang (2019) proposed the use of resource value analysis to reduce the energy and resource consumption, minimize negative impact of manufacturing enterprises on the environment and encourage sustainable development of the entities with limited resources. The articles by Choi, Thangamani, Kissock (2019); He, Liao, Bi, Guo (2019) present a systemic model for identifying and selecting innovative projects to improve the efficiency of use and storage of resources in the processing industry. Ting (2011) proposed measures of state support for energy and resource saving at the paper producing enterprises by introducing innovative technologies into production. Dobes et al. (2017) developed a comprehensive tool to identify potential sources of funding for innovative resource saving projects at agri-food enterprises in Central Europe. Scientists Nofal, Yusof (2013); Chofreh, Goni, Klemeš (2017) considered methods of implementing a system of sustainable resource planning to ensure the efficiency of energy and resource saving at processing enterprises and, as a consequence, their stable development and operation. Özbuğday, Fındık, Özcan, Başçı (2020) based on the study of the enterprises operating in energy-intensive industries in European countries, tested the hypothesis that investing in the innovative energy and resource saving projects will increase the growth rate of small and medium enterprises through increasing the efficiency of use of the available resources. Brüggemann, Stempin, Meier (2020) considered the specifics of data visualization in the energy management systems of industrial enterprises, which provides the use of new approaches to optimizing the use of resources in the production process.

Paying tribute to the above research, it is worth noting the need for further research to improve the management of energy and resource saving innovations at the processing enterprises. Therefore, the aim of the article is to develop a methodology for evaluating the economic efficiency of innovative projects on energy and resource saving.

The object of the study is processing enterprises using energy and resource saving equipment and technologies in their activities. The subject of the study is management of energy and resource saving innovations at the processing enterprises.

The theoretical basis of the research was fundamental propositions and scientific works on innovations in the field of energy and resource conservation and organization of their implementation in the production activities of enterprises of various sectors of the economy. The research methodology is based on the dialectical method of cognition of socio-economic phenomena, systematic and comprehensive approaches to the implementation of energy and resource-saving innovations in the activities of enterprises, which provided an opportunity to 
develop optimal methods for assessing the economic efficiency of innovative energy and resource saving projects.

The study used the following methods of cognition of economic phenomena and processes to solve the problems posed in the work: system analysis - to reveal the basics of the conceptual apparatus for the analysis of innovative projects on energy and resource saving; economic and mathematical modeling - to calculate the model for assessing the economic efficiency of the components of the energy and resource saving innovation projects; abstract-logical method - to formulate conclusions and make theoretical generalizations on the formation of methodology for assessing the economic efficiency of innovative projects on energy and resource saving.

The method of evaluating economic efficiency of innovative energy and resource saving projects, proposed as a result of the study, can be used in the process of the integrated management of the energy and resource saving innovations at the processing enterprises by implementing basic standards of resource management and taking into account possible risks.

\section{Research results and discussion}

We believe that analyzing the effectiveness of innovative energy and resource saving projects at the processing enterprises, it is advisable to compare two alternative situations when the enterprise implements or does not implement these projects. In a modified form, this situation can be represented as formula (1):

$$
\mathrm{P}=\Delta \mathrm{P}_{\mathrm{p} . \mathrm{r} .}-\Delta \mathrm{K}_{\mathrm{p} . \mathrm{r} .}
$$

where $P$ is profit generated by resource savings achieved in the process of implementing the program of resource saving innovations;

$\Delta P_{\text {p.r. }}$ are profit changes caused by resource savings achieved in the process of implementing the program of resource saving innovations;

$\Delta K_{\text {p.r. }}$ are changes in costs caused by resource savings achieved in the process of implementing the program of resource saving innovations;

This approach characterizes the economic efficiency of the energy and resource saving innovation projects in the most general form. Its detailed study, however, requires the use of a more advanced apparatus.

Based on the methods of analysis of investment projects (Petryk, Semenov, Hnatenko, Samiilenko, Rubezhanska, Patsarniuk, 2020; Samborskyi, Isai, Hnatenko, Parkhomenko, Rubezhanska, Yershova, 2020; Hnatenko, Orlova-Kurilova, Shtuler, Serzhanov, Rubezhanska, 2020; Goncharov, Zos-Kior, Rakhmetulina, 2013; Ganushchak-Efimenko, Hnatenko, Kozhushko, Rębilas, Rubezhanska, Krakhmalova, 2020), the economic efficiency of the energy and resource saving projects at the processing enterprises can be determined using a system of indicators that reflect the ratio of costs and results. These indicators include: $P V$ - present value, NPV - net present value; $I R R$ - internal rate of return of the project; $P B P$ - payback period; $P I$ - profitability index and $M I R R$ - modified internal rate of return. Let us consider these indicators in more detail.

Thus, $P V$ characterizes the present value of the cash flow generated by the energy and resource saving project (2):

$$
P V=\frac{P_{m}}{(1+r)^{m}}
$$

where $\mathrm{m}$ is the number of years during which the calculations are performed.

The $N P V$ indicator is calculated as the difference between the values of resource savings discounted before the start of the project and values associated with implementation of the project on the energy and resource saving innovations (3): 


$$
\mathrm{NPV}=\sum \mathrm{NPV}_{\mathrm{n}},
$$

where $n$ is the number of individual measures for the implementation of the energy and resource saving innovations.

Let $P$ and $S$ be respectively discounted values of the profit generated by resource savings and costs associated with implementation of the project on energy and resource-saving/conservation innovations. Then (4-5):

$$
\begin{gathered}
P=\sum_{t=1}^{T} \frac{p(t)}{(1+i)^{t}}, \\
\sum_{t=1}^{T} S=s(t) /(1+i)^{t}, i \geq K(t)+V+h,
\end{gathered}
$$

where $p(t)$ is income/profit generated by resource savings during period $t$;

$s(t)$ is cost of implementing the program of resource saving innovations in the period $t$;

$i$ is discount rate;

$t=(1, \ldots, T)$ is time period.

Based on (2) and (3), net discounted income from energy and resource savings resulting from the project on energy and resource saving innovations can be calculated by expression (6):

$$
N P V=P-S=\sum_{t=1}^{T} \frac{p(t)}{(1+i)^{t}}-\sum_{t=1}^{T} \frac{s(t)}{(1+i)^{t^{*}}}
$$

Since the $N P V$ indicator is significantly influenced by the discount rate $(i)$, it is advisable to assess and analyze the economic efficiency of the energy and resource saving innovation projects by calculating the dependence of the $N P V$ on the discount rate.

The IRR indicator is the $i^{*}$ discount rate, at which the discounted value of the energy and resource savings expected from an innovative project on energy and resource saving at the processing plant is equal to the discounted cost of its implementation, i.e. the total economic effect covers the amount of borrowings, interest on them and the corporate income tax. So (7):

$$
\begin{gathered}
\operatorname{IRR}=\mathrm{i}^{*} ;\left\{\operatorname{NPV}\left(\mathrm{i}^{*}\right)=0\right\}, \\
\mathrm{NPV}=\sum_{\mathrm{t}=1}^{\mathrm{T}} \frac{\mathrm{p}(\mathrm{t})-\mathrm{s}(\mathrm{t})}{(1+\operatorname{IRR})^{\mathrm{t}}}=0 .
\end{gathered}
$$

The value of the indicator is the threshold value of the discount rate at which the implementation of the project is appropriate. The decision on project financing should be made on the basis of comparing $I R R$ with the normative profitability of the project on the energy and resource saving innovations. Furthermore, the higher the value of $I R R$ and the greater the difference between its value and the normalized discount rate, the greater the margin of financial strength of the project is.

$P B P$ is the payback period of an innovative energy and resource saving project, defined as the period of time $t^{*}$ required to recoup the investment with the money saved during the project implementation and accumulated by the enterprise. Analytically, the payback period of the project is defined as (8):

$$
\mathrm{PBP}=\mathrm{t}^{*} ;\left\{\mathrm{NPV}\left(\mathrm{t}^{*}\right)=0\right\} .
$$


The implementation of the project is appropriate if the calculated payback period does not exceed the repayment period of the loan agreed with the investor.

$P I$ is profitability index which reflects the relative profitability (discounted profitability) of the project (9):

$$
P I=\sum_{t=1}^{\mathrm{T}} \frac{p(t)}{(1+r)^{t}} / \sum_{t=1}^{\mathrm{T}} \frac{s(t)}{(1+r)^{t}}
$$

This indicator characterizes the efficiency of investment in the project implementation and must meet $P I>1$ condition.

Another indicator, similar in content to $I R R$, is a modified internal rate of return - MIRR calculated by formula (10):

$$
\sum_{t=1}^{T} \frac{K(t)}{(1+g)^{t}}=\sum_{t=1}^{T} \frac{P(t) \cdot(1+g)^{t}}{(1+M I R R)^{t}} .
$$

To assess the future costs and results of innovative projects on energy and resource saving, it is necessary to determine the limits of the calculation period, the duration of which (planning horizon) is taken based on the duration of the development and implementation of the energy and resource saving innovations, achievement of the set characteristics of savings from the measures realization, and investor requirements.

To determine the economic efficiency of the project on the energy and resource saving innovations, we consider it necessary to introduce the following indicators:

$C J_{j}$ are funds invested in the $j$ measure;

$N P V_{j}$ is return on the $j$ measure;

$P J_{j}$ is profitability of the $j$ measure.

Let $J V$ be the funding for the project under study. Then (11):

where $n$ is the number of measures.

$$
\mathrm{JV} \geq \sum_{1}^{\mathrm{n}} \mathrm{CJ}_{\mathrm{j}}
$$

Return on the project (12):

$$
\mathrm{NPV}=\sum N P V_{j}
$$

Given that the considered projects are implemented during one year, their present discounted value will be determined as follows (13):

$$
\mathrm{PV}=\frac{\mathrm{P}}{1-\mathrm{i}^{\prime}}
$$

where $P$ is the expected inflow of funds from savings resulting from the program implementation;

$i$ is discount rate.

Without taking into account the probabilistic approach, each indicator can be given a certain weight indicator through expert assessments and build a rating of energy and resource saving measures. With this approach:

1) the greater the $N P V$ in relation to $C J$, the higher the "weight" of $N P V$

2 ) the greater the $P J$ and $I R R$ in relation to the return on the assets of the enterprise, the higher the "weight" of $P V$

One of the main problems in assessing the efficiency of innovations is the uncertainty of the expected return. Due to the uncertainty of cash flows received from the implementation of the energy and resource saving project, there is some risk of investing in the energy and resource saving 
innovations. To assess the risk, it is advisable to use the coefficient of variation ("iota-coefficient") (14):

where $J$ is the iota-coefficient,

$$
\mathrm{J}=\frac{\sigma}{\mathrm{M}^{\prime}}
$$

$\sigma$ is the standard deviation;

$M$ is mathematical expectation of the estimated value.

For the draft measures (15):

$$
\mathrm{J}=\frac{\sigma \mathrm{NPV}}{\mathrm{NPV}}
$$

where $\sigma N P V$ is the standard deviation of the net present value from resource savings during project implementation.

The standard deviation $N P V$ of the project is determined using the theorem of the probability theory (16):

$$
\mathrm{D}=\sum_{\mathrm{j}=1}^{\mathrm{n}} \mathrm{D},
$$

where $D=\sigma^{2}$ is variance of the $N P V$ project.

$D=\sigma_{i}^{2}$ is variance of individual project measures. Then (17):

$$
\sigma=\sqrt{\sum_{j=1}^{n} \sigma_{j}^{2}}
$$

It gives us the iota-coefficient of the innovative project on the energy and resource saving at a processing plant (18):

$$
\mathrm{J}_{\mathrm{NPV}}=\sqrt{\sum_{\mathrm{j}=1}^{\mathrm{n}} \sigma_{\mathrm{j}}^{2} / \sum_{\mathrm{j}=1}^{\mathrm{n}} \mathrm{NPV} \mathrm{V}_{\mathrm{j}}}
$$

In the simplest case, if the "weights" of the measures that can be included in the project have the same indicators (19):

$$
\sigma=\sigma_{\mathrm{m}} ; \mathrm{NPV}_{\mathrm{j}}=\mathrm{NPV}_{\mathrm{m}}
$$

From (18) we obtain the ratio (20):

$$
\begin{gathered}
J=J_{\mathrm{m}} / \sqrt{\mathrm{n}}, \\
\mathrm{J}=\sigma_{\mathrm{m}} / \mathrm{NPV}_{\mathrm{m}}{ }^{\prime}
\end{gathered}
$$

where $J_{m}$ is the iota-coefficient of the measure, which is equal to the ratio of the project financing fund $(C J)$ to the cost of financing the medium-sized measure.

The obtained ratio is equivalent to (21):

$$
\operatorname{PFR}=\mathrm{JFE} / \sqrt{\mathrm{n}},
$$

where $P F R$ is the average risk of the insurer per firm;

$J F E$ is individual risk of the firm;

$n$ is the number of identical insured firms.

Thus, the risk of project implementation is lowered by reducing the average cost of the measures included. 
Taking into account the risks, the guaranteed level of net present value from energy and resource savings during the implementation of the energy and resource saving project can be determined using the definition of the confidence interval of a random variable. It will be (22):

$$
\mathrm{NPV} \geq \mathrm{NPV}-\mathrm{t} \cdot \sigma_{\mathrm{NPV}}=\mathrm{NPV}\left(1-\mathrm{t} \cdot \mathrm{J}_{\mathrm{NPV}}\right),
$$

where $\sigma_{N P V}$ is the standard deviation of the net discounted value of the project;

$J_{N P V}$ is iota-coefficient of the project;

$t$ is the coefficient of the confidence interval.

To evaluate the project, one can use the indicator of the guaranteed $N P V$, which is proposed to be determined by using the following formula (23):

$$
\mathrm{NG}=\frac{\mathrm{NPV}}{\mathrm{NPV}}=1-\mathrm{t} \cdot \mathrm{J}_{\mathrm{NPV}}
$$

where $N G$ is an indicator of the guaranteed $N P V$ of the project on the energy and resource saving innovations.

By the theorem on the variance of linear functions of random variables (24):

$$
\begin{aligned}
& \mathrm{D}_{\mathrm{NPV}}=\sum \mathrm{D}_{\mathrm{NPV}_{\mathrm{j}}}=\sum\left[\sigma_{\mathrm{PV}_{\mathrm{j}}} /(1+\mathrm{i})\right]^{2}=\frac{1}{(1+\mathrm{i})^{2}}\left(\sum \sigma_{\mathrm{PV}_{\mathrm{j}}}\right)^{2} . \\
& \mathrm{J}_{\mathrm{NPV}}=\frac{\sqrt{\mathrm{D} N P V}}{\mathrm{M}(\mathrm{NPV})}=\frac{\frac{1}{1+\mathrm{i}} \sum \sigma_{\mathrm{PV}_{\mathrm{j}}}}{1}=\frac{\sqrt{\sum \sigma_{\mathrm{PV}_{\mathrm{j}}^{2}}}}{\sum \mathrm{PV}_{\mathrm{j}}}=\frac{\sqrt{\sum \sigma_{\mathrm{PV}_{\mathrm{j}}^{2}}}}{\mathrm{PV}} . \\
& \mathrm{PJ}=\frac{\mathrm{PV}}{\mathrm{GJ}}=\frac{\sum \mathrm{PV}_{\mathrm{i}}}{\sum \mathrm{GJ}_{\mathrm{j}}} \text {. } \\
& \mathrm{D}_{\mathrm{PV}}=\left(\frac{1}{\sum \mathrm{GJ}_{\mathrm{j}}}\right)^{2} \cdot \sum \mathrm{D}_{\mathrm{PV}_{\mathrm{j}}} \text {. } \\
& \mathrm{J}_{\mathrm{PJ}}=\frac{\sigma_{\mathrm{PJ}}}{\mathrm{PJ}}=\frac{\sqrt{\mathrm{D}}}{\frac{\sum \mathrm{PV}_{\mathrm{j}}}{\sum \mathrm{GJ}_{\mathrm{j}}}}=\frac{\sqrt{\sum \sigma^{2} /\left(\sum \mathrm{GJ}\right)^{2}}}{\sum \mathrm{PV}_{\mathrm{j}} / \sum \mathrm{GJ}_{\mathrm{j}}}=\frac{\sqrt{\sum \sigma_{\mathrm{PV}}^{2}}}{\sum \mathrm{PV}_{\mathrm{j}}}=\mathrm{J}_{\mathrm{PV}} \text {. }
\end{aligned}
$$

For $I R R$, a similar expression would be as follows (25):

$$
\begin{gathered}
\mathrm{JRR}=\frac{\sum \mathrm{PV}}{\sum \mathrm{GJ}}-1 . \\
\mathrm{D}_{\mathrm{PV}}=\left(\frac{1}{\sum \mathrm{GJ}}\right)^{2} \sum \mathrm{D}_{\mathrm{PV}_{\mathrm{j}}} . \\
\mathrm{J}_{\mathrm{IRR}}=\frac{\frac{1}{\mathrm{GJ}} \sqrt{\sum \sigma_{\mathrm{PV}}^{2}}}{\frac{\sum \mathrm{PV}-\mathrm{GJ}}{\mathrm{GJ}}}=\frac{\sqrt{\sum \sigma_{\mathrm{PV}}^{2}}}{\sum \mathrm{PV}\left(1-\frac{\mathrm{GJ}}{\mathrm{PV}}\right)}=\frac{\mathrm{J}_{\mathrm{PV}}}{\left(1-\frac{\mathrm{GJ}}{\mathrm{PV}}\right)} .
\end{gathered}
$$

For $N P V(25)$ :

For PJ (26):

$$
\mathrm{NG}=1-\mathrm{tJ} \mathrm{PV}
$$

For $\operatorname{IRR}(27)$ :

$$
P G=1-\mathrm{tJ}_{\mathrm{PV}} .
$$

$$
\mathrm{IG}=\left[\left(1-\mathrm{tJ}_{\mathrm{PV}}\right) /\left(1-\frac{\mathrm{GJ}}{\mathrm{PV}}\right)\right]
$$


These indicators depend on the number of measures included in the innovative project on energy and resource saving, confidence probability; $N G$ and $\frac{G J}{P V}$ ratio.

But under current conditions, not only the flow of money from energy and resource savings, but also the level of interest rates on loans and discount rates are unstable. Therefore, it is necessary to clarify the definition of the coefficient of variation NPV, which depends on them.

Numerical characteristics of functions of a random variable are known to be determined by decomposing them into a Taylor series, and are usually limited to a linear decomposition. Then for the project on energy and resource saving we have (28):

$$
\mathrm{NPV}=\sum_{\mathrm{j}=1}^{\mathrm{n}} \frac{\mathrm{PV}}{1+\mathrm{i}}-\mathrm{CJ}
$$

where $N P V$ is expected value - mathematically expected net present value;

$P V_{j}$ is the expected value of the return on the $j$ measure;

$G J$ is cost of financing the energy and resource saving project.

The variance of the function of random variables is defined as (29):

$$
D=\sum_{\mathrm{K}=1}^{\mathrm{m}}\left(\frac{\partial \varphi}{\partial \mathrm{x}_{\mathrm{k}}}\right)^{2} \mathrm{D}_{\mathrm{xk}}+2 \sum_{\mathrm{m}<\mathrm{k}}\left(\frac{\partial \varphi}{\partial \mathrm{x}_{\mathrm{k}}}\right) \cdot\left(\frac{\partial \varphi}{\partial \mathrm{x}_{\mathrm{m}}}\right) \mathrm{k}_{\mathrm{mk}} \cdot \sigma_{\mathrm{x}_{\mathrm{m}}} \sigma_{\mathrm{xk}},
$$

where: $D$ is the variance of the function;

$D_{x k}$ is the variance of the $\mathrm{k}$ argument;

$\frac{\partial \varphi}{\partial x_{k}}$ are individual derivatives.

If there is no correlation between the random arguments of the function, then the last term in (29) is zero.

If the return from the project measure is correlated, then for $P V(30)$ :

$$
D=\sum_{j=1}^{M} D_{j}+2 \sum_{j<k} k_{j} \cdot \sigma_{j} \cdot \sigma_{k} .
$$

If all program measures are equally correlated $\sigma_{j}=\sigma ; k_{i k}=k$, the expression will take the form (31):

$$
\mathrm{D}=\sum_{\mathrm{j}=1}^{\mathrm{n}} \sigma^{2}+2 \sum \mathrm{k} \sigma^{2}=\sigma^{2}\left[\mathrm{n}+2 \sum_{\mathrm{j}=1} \mathrm{k}\right],
$$

where $k$ meets the condition: $-1<k<+1$.

Then the value of the iota-coefficient for the present value of the cash flow will be determined by formula (32):

$$
J=\frac{\sqrt[\sigma]{\mathrm{n}+2 \sum \mathrm{k}_{\mathrm{j}_{\mathrm{k}}}}}{\sum \mathrm{PV}_{\mathrm{j}}}=\frac{\sqrt[\sigma]{\mathrm{n}+2 \sum \mathrm{k}_{\mathrm{j}_{\mathrm{k}}}}}{\mathrm{PV}_{\mathrm{m}} \cdot \mathrm{n}}=\mathrm{J}_{\mathrm{m}} \cdot \sqrt{\frac{1}{\mathrm{n}}+\frac{2 \sum \mathrm{k}_{\mathrm{j}_{\mathrm{k}}}}{\mathrm{n}^{2}}}
$$

From (32), having performed mathematical transformations, we can obtain the following formula for estimating the iota-coefficient, which characterizes the overall risk of the project (33):

$$
\frac{\mathrm{J}}{\mathrm{J}_{\mathrm{m}}}=\sqrt{\frac{1}{\mathrm{n}}+\mathrm{k} \frac{\mathrm{n}-1}{\mathrm{n}} .}
$$


In addition, we believe that in determining the economic efficiency of the energy and resource saving innovation projects, it is necessary to take into account the impact of volatile discount rates. In the first approximation (34):

$$
\mathrm{D}_{\mathrm{NPV}}=\left(\frac{\partial \mathrm{NPV}}{\partial \mathrm{PV}}\right)^{2} \mathrm{D}_{\mathrm{PV}}^{2}+\left(\frac{\partial \mathrm{NPV}}{\partial \mathrm{i}}\right)^{2} \mathrm{D}_{\mathrm{i}}^{2}
$$

where $D_{N P V}$ is variance of the net present value from the project implementation; $D_{P V}$ - variance of the present value of the cash flow generated by the project; $D_{i}^{2}$ - variance of the discount rate;

$\partial$ - partial derivatives.

$$
\begin{gathered}
\mathrm{NPV}=\frac{\mathrm{PV}_{\mathrm{j}}}{1+\mathrm{i}}-\mathrm{CJ} . \\
\frac{\partial \mathrm{NPV}}{\partial \mathrm{PV}}=\left(\frac{1}{1+\mathrm{i}}\right) . \\
\mathrm{D}_{\mathrm{NPV}}=\left(\frac{1}{1+\mathrm{i}}\right)^{2} \mathrm{D}_{\mathrm{PV}}+\mathrm{PV}^{2} \frac{1}{(1+\mathrm{i})^{2}} \cdot \mathrm{D}_{\mathrm{i}} . \\
\sigma_{\mathrm{NPV}}=\sqrt{\frac{1}{(1+\mathrm{i})^{2}} \cdot \sigma_{\mathrm{PV}}^{2}+\mathrm{PV}^{2} \frac{1}{(1+\mathrm{i})^{4}} \sigma_{\mathrm{i}}^{2}}=\frac{1}{1+\mathrm{i}} \sqrt{\sigma_{\mathrm{PV}}^{2}+\mathrm{PV}^{2} \frac{1}{(1+\mathrm{i})^{2}} \sigma_{\mathrm{i}}},
\end{gathered}
$$

where $\sigma_{i}$ is the standard deviation of the discount rate

$$
\mathrm{J}_{\mathrm{NPV}}=\frac{\sigma_{\mathrm{NPV}}}{\mathrm{NPV}}
$$

where $\sigma_{N P V}$ is the standard deviation of the net present value from project implementation.

$$
\begin{aligned}
& \mathrm{NPV}=\frac{1}{1+\mathrm{i}}[\mathrm{PV}-\mathrm{GJ}(1+\mathrm{i})] \text {. } \\
& \mathrm{NPV}=\frac{\mathrm{PV}}{1+\mathrm{i}}\left[1-(1+\mathrm{i}) \frac{\mathrm{GJ}}{\mathrm{PV}}\right] \text {. } \\
& \mathrm{NPV}=\frac{\mathrm{PV}}{1+\mathrm{i}}\left[1-(1+\mathrm{i}) / \frac{\mathrm{GJ}}{\mathrm{PV}}\right] \text {. } \\
& \mathrm{J}_{\mathrm{NPV}}=\frac{\sigma_{\mathrm{NPV}}}{\mathrm{NPV}}=\frac{\frac{1}{1+\mathrm{i}} \sqrt{\sigma_{\mathrm{PV}}^{2}+\mathrm{PV}^{2} \frac{1}{(1+\mathrm{i})} \sigma_{\mathrm{i}}^{2}}}{\frac{\mathrm{PV}}{1+\mathrm{i}}[1-(1+\mathrm{i}) / \mathrm{PJ}]}=\frac{\sqrt{\left(\frac{\sigma_{\mathrm{PV}}}{\mathrm{PV}}\right)^{2}+\frac{1}{(1+\mathrm{i})^{2}} \sigma_{\mathrm{i}}^{2}}}{1-(1+\mathrm{i}) / \frac{\mathrm{G} J}{\mathrm{PJ}}} \text {. } \\
& \mathrm{J}_{\mathrm{i}}=\sigma_{\mathrm{i}} / \mathrm{i} \rightarrow \sigma_{\mathrm{i}}=\mathrm{iJ}_{\mathrm{i}} . \\
& \mathrm{J}_{\mathrm{NPV}}=\sqrt{\mathrm{J}_{\mathrm{PV}}^{2}+\frac{\mathrm{i}^{2} \mathrm{~J}_{\mathrm{i}}^{2}}{(1+\mathrm{i})^{2}} /[1-(1+\mathrm{i}) / \mathrm{PJ}]} \text {. } \\
& \mathrm{J}_{\mathrm{NPV}}=\mathrm{J}_{\mathrm{PV}} \sqrt{1+\left(\frac{\mathrm{J}_{\mathrm{i}}}{\mathrm{J}_{\mathrm{PV}}}\right)^{2} \frac{\mathrm{i}^{2}}{(1+\mathrm{i})^{2}} /\left[1-(1+\mathrm{i}) / \frac{\mathrm{PJ}}{\mathrm{PV}}\right]} . \\
& \sigma_{\mathrm{PV}}=\sqrt{\sum \sigma_{\mathrm{PV}_{\mathrm{j}}}} ; \mathrm{PV}=\sum \mathrm{PV}_{\mathrm{i}} \text {. } \\
& \mathrm{PJ}=\frac{\sum \mathrm{PV}}{\sum \mathrm{CJ}}>1 \text {. }
\end{aligned}
$$


Thus, using the obtained expressions that take into account the instability of discount rates for $N P V(38)$ :

$$
\mathrm{NG}=1-\mathrm{tJ}_{\mathrm{NPV}}
$$

where $t$ depends on $n$ (number of measures in the program of resource saving innovations) and the confidence probability $\mathrm{P}$.

Thus, we have identified seven parameters the economic efficiency of innovative energy and resource saving projects at the processing enterprises depends on, namely:

number of measures of the project on the energy and resource saving innovations (n);

discount rate (i);

profitability of the energy or resource saving innovation (r);

iota-coefficients of savings from the implementation of each of the project measures $\left(\mathrm{J}_{\mathrm{PV}}\right)$;

iota-coefficient of the discount rate $\left(J_{j}\right)$;

the ratio of the iota-coefficient of the discount rate and the iota-coefficient of the cash flow generated by the energy and resource saving innovations $\left(J / J_{p v}\right)$;

correlation coefficients between the amount of savings from each of the energy and resource saving project measures $(\mathrm{k})$.

At the same time, it should be emphasized that the effective management of innovative energy and resource saving projects requires improvement of the management mechanism of the processing enterprises, its focus on the program-target planning and flexible management structures that ensure the development of these entities in a rigid competition and constant changes in the environment.

\section{Conclusion}

As a result of the study aimed at optimizing management of innovative energy and resource saving projects at the processing enterprises, it is proposed to improve the methodology for determining the economic efficiency of these projects by assessing the risk of each measure included in the project and the project as a whole. In this regard the selection of measures for a particular innovative project on energy and resource saving should be based on determining the maximum economic efficiency and minimum level of risk of each of them. Optimal in terms of risk project structure is ensured through effective risk diversification, which consists in selection of measures aimed at saving energy and diverse types of resources. Risk reduction should be ensured by the introduction of an effective management system of the processing enterprise, focused on the implementation of energy and resource saving projects.

The use of the proposed method of assessing the economic efficiency of innovative projects on energy and resource saving will promptly improve solutions in the process of integrated management of the energy and resource saving innovations at the processing plants by implementing basic standards of resource management and taking into account possible risks.

\section{References}

Bilan, Y., Zos-Kior, M., Nitsenko, V., Sinelnikau, U., Ilin, V. (2017). Projecting the social component of the efficient management of land resources // Journal of Security and Sustainability Issues. Vol.7. No.2: 287-300. Retrieved from: https://doi.org/10.9770/jssi.2017.7.2(9) [28 10 2020].

Brüggemann, H., Stempin, S., Meier, J. (2020). Consideration of digitalization for the purpose of resource efficiency in a learning factory // Procedia Manufacturing. Vol.45: 140-145. - Retrieved from: https://doi.org/10.1016/j.promfg.2020.04.085 [28 10 2020].

Cemil Özbuğday, F., Fındık, D., Metin Özcan, K., Başçı, S. (2020). Resource efficiency investments and firm performance: Evidence from European SMEs // Journal of Cleaner Production. Vol.252. - Retrieved from: https://doi.org/10.1016/j.jclepro.2019.119824 [28 10 2020]. 
Choi, J., Thangamani, D., Kissock, K. (2019). A systematic methodology for improving resource efficiency in small and medium-sized enterprises // Resources, Conservation and Recycling. Vol.147: 19-27. - Retrieved from: https://doi.org/10.1016/j.resconrec.2019.04.015. [28 10 2020].

Cunha, P., Neves, S., Marques, A., Serrasqueiro, Z. (2020). Adoption of energy efficiency measures in the buildings of micro-, small- and medium-sized Portuguese enterprises // Energy Policy. Vol.146. - Retrieved from: https://doi.org/10.1016/j.enpol.2020.111776 [28 10 2020].

Dobes, V., Fresner, J., Krenn, C., Růžička, P., Rinaldi, C., Cortesi, S., Chiavetta, C., Zilahy, G., Kochański, M., Grevenstette, P., Graaf, D., Dorer, C. (2017). Analysis and exploitation of resource efficiency potentials in industrial small and medium-sized enterprises - Experiences with the EDIT Value Tool in Central Europe // Journal of Cleaner Production. Vol.159: 290-300. - Retrieved from: https://doi.org/10.1016/j.jclepro.2017.05.017 [28 102020 ].

Ganushchak-Efimenko, L., Hnatenko, I., Kozhushko, R., Rębilas, R., Rubezhanska, V., Krakhmalova, T. (2020). Optimization models of investment management in the activities of innovative enterprises // Management Theory and Studies for Rural Business and Infrastructure Development. Vol.42. No.3: 225-234. - Retrieved from: https://doi.org/10.15544/mts.2020.22 [28 10 2020].

Gholamzadeh Chofreh, A., Ariani Goni, F., Jaromír Klemeš, J. (2017). Development of a roadmap for Sustainable Enterprise Resource Planning systems implementation (part II) // Journal of Cleaner Production. Vol.166: 425-437. - Retrieved from: https://doi.org/10.1016/j.jclepro.2017.08.037 [28 10 2020].

Goncharov, V., Zos-Kior, M., Rakhmetulina, Zhibek B. (2013). The investment component of Ukrainian agrarian enterprises' development in conditions of land reform // Actual problems of the economy. Vol.10. No.148: 118125. [28 10 2020].

Gryshko, V., Zos-Kior, M., Zerniuk, O. (2018). Integrating the BSC and KPI systems for improving the efficiency of logistic strategy implementation in construction companies // International Journal of Engineering \& Technology. Vol.7. No.3.2: 131-134. - Retrieved from: https://doi.org/10.14419/ijet.v7i3.2.14389 [28 102020 ].

He, Y., Liao, N., Bi, J. \& Guo, L. (2019). Investment decision-making optimization of energy efficiency retrofit measures in multiple buildings under financing budgetary restraint // Journal of Cleaner Production. Vol. 215: 1078-1094. - Retrieved from: https://doi.org/10.1016/j.jclepro.2019.01.119 [28 10 2020].

Hnatenko, I., Kuksa, I., Naumenko, I., Baldyk, D., Rubezhanska, V. (2020). Infrastructure of innovation enterprise: features of formation and regulation in modern market conditions // Management Theory and Studies for Rural Business and Infrastructure Development. Vol. 42. No.1: 97-104. - Retrieved from: https://ejournals.vdu.lt/index.php/mtsrbid/article/view/927 [28 10 2020].

Hnatenko, I., Orlova-Kurilova, O., Shtuler, I., Serzhanov, V., Rubezhanska, V. (2020). An Approach to Innovation Potential Evaluation as a Means of Enterprise Management Improving // International Journal of Supply and Operations Management. Vol.7 No.1: 112-118. - Retrieved from: https://doi.org/10.22034/IJSOM.2020.1.7 [28 10 2020].

Kuksa, I., Hnatenko, I., Orlova-Kurilova, O., Moisieieva, N., Rubezhanska, V. (2019). State regulation of innovative employment in the context of innovative entrepreneurship development // Management Theory and Studies for Rural Business and Infrastructure Development. Vol.41. No.2: 228-236. - Retrieved from: https://doi.org/10.15544/mts.2019.19 [28 10 2020].

Kuksa, I., Shtuler, I., Orlova-Kurilova, O., Hnatenko, I., Rubezhanska, V. (2019). Innovation cluster as a mechanism for ensuring the enterprises interaction in the innovation sphere // Management Theory and Studies for Rural Business and Infrastructure Development. Vol.41. No.4: 487-500. - Retrieved from: https://doi.org/10.15544/mts.2019.39 [28 10 2020].

Li, Z., Zeng, H., Xiao, X., Cao, J., Yang, C., Zhang, K. (2019). Resource value flow analysis of paper-making enterprises: A Chinese case study // Journal of Cleaner Production. Vol.213: 577-587. - Retrieved from: https://doi.org/10.1016/j.jclepro.2018.12.158 [28 10 2020].

McAdam, M., McAdam, R., Dunn, A. \& McCall, C. (2014). Development of small and medium-sized enterprise horizontal innovation networks: UK agri-food sector study // International Small Business Journal. Vol.32. No.7: 830-853. - Retrieved from: https://doi.org/10.1177/0266242613476079 [28 10 2020].

Nofal, M., Yusof, Z. (2013). Integration of Business Intelligence and Enterprise Resource Planning within Organizations // Procedia Technology. Vol.11: 658-665. - Retrieved from: https://doi.org/10.1016/j.protcy.2013.12.242 [28 10 2020].

Petryk, O., Semenov, A., Hnatenko, I., Samiilenko, A., Rubezhanska, V., Patsarniuk, O. (2020). Conceptual model for assessing the investment attractiveness of innovative projects of industrial enterprises // Accounting. Vol.6. No.7: 1345-1350. - Retrieved from: https://doi.org/10.5267/j.ac.2020.8.015 [28 10 2020].

Samborskyi, O., Isai, O., Hnatenko, I., Parkhomenko, O., Rubezhanska, V., Yershova, O. (2020). Modeling of foreign direct investment impact on economic growth in a free market // Accounting. Vol.6. No.5: 705-712. - Retrieved from: https://doi.org/10.5267/j.ac.2020.6.014 [28 10 2020].

Stroud, D., Evans, C., Weinel, M. (2020). Innovating for energy efficiency: Digital gamification in the European steel industry // European Journal of Industrial Relations. Vol.26. No.4: 419-437. - Retrieved from: https://doi.org/10.1177/0959680120951707 [28 10 2020]. 
Ting, G. (2011). Researches of Developing Strategies and Guarantee Mechanism of Energy Saving and Emission Reduction on Paper-making Enterprises-Case Study of Shandong Haiyun High-Efficiency Ecological Park // Energy Procedia. Vol.5: 674-678. - Retrieved from: https://doi.org/10.1016/j.egypro.2011.03.119 [28 10 2020].

Xu, Y., Wang, Z., Chiu, Y.-H., Ren, F. (2020). Research on energy-saving and emissions reduction efficiency in Chinese thermal power companies // Energy \& Environment. Vol.31. No.5: 903-919. - Retrieved from: https://doi.org/10.1177/0958305X19882375 [28 10 2020].

Zhang, K., Li, W., Han, Y., Geng, Z., Chu, C. (2020). Production capacity identification and analysis using novel multivariate nonlinear regression: Application to resource optimization of industrial processes // Journal of Cleaner Production. Vol.268. - Retrieved from: https://doi.org/10.1016/j.jclepro.2020.122182 [28 10 2020].

Zhang, Y., Huang, T., Yang, D. (2020). Impact of firms' energy-saving effort and fixed asset characteristics on energy savings // Journal of Cleaner Production. Vol.268. - Retrieved from: https://doi.org/10.1016/j.jclepro.2020.122182 [28 10 2020]. 